\title{
A GUIDING FRAMEWORK FOR THE DEVELOPMENT OF A TRANS-DISCIPLINARY COMMUNITY MENTAL HEALTH STUDENT TEACHING AND LEARNING PLATFORM
}

\author{
J. M. Jansen* \\ M. du Preez* \\ R. Exner* \\ L. Stroud*
}

e-mail: Jennifer.Jansen@nmmu.ac.za

*Psychology Department

Nelson Mandela University

Port Elizabeth, South Africa

\section{ABSTRACT}

Establishing a trans-disciplinary mental health platform could contribute to outreach and service training agendas in a higher educational context as engagement is a higher education priority for all universities. The purpose of the platform described in the article provides an opportunity for students to learn from each other, with each other and about each other, across a variety of disciplines in one university, while also effectively addressing the needs of the surrounding community. This article records the background to the establishment of a unique multi-disciplinary university-community collaborative initiative in South Africa by using a self-reflective and participatory action learning and action research approach which is learner centred, project-based, and aimed at social justice. Indeed, transformative teaching has been one of the teaching methodologies which has guided this initiative. Furthermore, this student, teaching and learning platform also identifies lessons learnt and creates a guiding framework for the establishment of similar projects in other communities. First, and most importantly, this platform contributes to providing a framework to guide and encourage future establishments of similar universitycommunity collaborative engagement endeavours and, secondly, it highlights the requirements for sustaining services to communities when senior students exit their university programmes, and new students enter.

Key words: action research, community engagement, higher education, mental health, South Africa, trans-disciplinary collaboration, transformational teaching

\section{INTRODUCTION}

The importance of transformative learning and reflective practice is regarded by many as an essential characteristic for professional competence as it develops autonomous thinking in 
psychological, behavioural and convictional domains (Mann, Gordon and MacLeod 2009). To learn effectively from one's experience, according to Boud, Keogh and Walker (1985), is critical in developing and maintaining competence across a practice lifetime. As Boud (1999) asserts, the emergence of reflective practice is part of a paradigm change in education that acknowledges the need for students and educators to think and act professionally as an integral part of learning, rather than insisting that students must learn the theory before they can engage in practice. However, the evidence to support these curricular interventions and innovations often remain largely theoretical. Furthermore, as one's professional identity develops, there are aspects of learning that require an understanding of one's personal beliefs, attitudes and values. Epstein (1999) points out that within the context of one's professional culture, self-reflection offers an explicit approach to this integration of self-learning. For health science educators, who are educators as well as practitioners, their professional lives doubly intersect with the selfreflective imperative.

Building integrated knowledge bases requires an active approach to learning that leads to understanding and linking new concepts to existing knowledge. Bandura (1986) argues that these capabilities (to merge new information with existing knowledge) may underpin the development of a professional who is self-aware, and therefore engages in self-monitoring. Yet, Mann, Gordon and MacLeod (2009), as well as Clark (2006), state that there is limited literature available to guide health science educators in their work to develop their reflective ability as professionals. Furthermore, such literature is dispersed across several fields, including nursing and psychology, posing a challenge as far as terminology is involved, as each field has differing underlying disciplinary values, and differing cognitive and normative maps. Consequently, selfreflection may be particularly useful when used as an inter-disciplinary learning strategy to assist students in connecting and integrating new learning with existing skills. Self-reflection allows students to explicitly integrate the affective aspects of learning, and also aid with potentially traumatizing contexts and situations. This article presents a South African case study of a trans-disciplinary university-community collaborative initiative as a model platform for the mapping of new ways of learning, namely integrating academic knowledge and socially relevant and responsive clinical skills. That is to say, this article records the background to the formation of this platform, identifies lessons learned, and thereafter produces a framework for the establishment of such a platform by creating a set of replicable guidelines and suggestions for similar projects in other impoverished communities

Within the South African context, as shall be discussed below, there is a dire need for universities to facilitate transformational types of training within the health professions in 
collaboration with communities on a sustainable basis. It is believed that a community-centred paradigm will result in the enablement of multi-professional teams, and later, trans-professional teams, to practically promote health and well-being to individuals, families and communities.

When looking at traditional disciplinary-siloed ways of working each professional would be functioning by using only their own profession-related competencies which could restrict the broader holistic clinical picture of the client. Should health professional teams function in this siloed manner the bio-psycho-social needs of a client in an impoverished community will be over-looked. Innovative and responsive knowledge creation in the MPC takes place when all the health professional students share information regarding the client and also by practicing health delivery in this manner they also learn from each other, with each other and about each other. In turn the clients optimally benefit from the multiplicity of referral sources gleaned from all the professionals working in the MPC. For an 'at risk' community like Missionvale the 'one stop shop' approach benefits impoverished clients as their needs are attended to in a single setting at one particular time.

Traditionally multi-disciplinary teams in health sciences consist of a variety of health professionals from different disciplines that are co-opted to interact together for a shorter period of time, often reactively following on a crisis or problem that was identified. The uniqueness of the MPC's multi-disciplinary approach is that the members of the team came on board incrementally and proactively as the need for their services was identified. It is believed that this predicts more longitudinal sustainability and impactfulness. Usually multidisciplinary teams consist of traditional health professional students and professionals. At this clinic the community is an equal role player, which enhances the bi-directional and integrated creation and exchange of knowledge, learning and wellness. Since MPC is situated within an impoverished community we have appointed a dedicated community co-coordinator which makes this team unique as the coordinator keeps the MPC in touch with the needs of the community at grassroots level and also helps with translating when dealing with Xhosa speaking clients. Theoretical knowledge and insular disciplinary practices therefore translate into impactful and relevant praxis, which in turn provides a platform for the expansion of existing and the development of new knowledge.

Before 1996 mental health education at South African universities was predominantly theoretical with little opportunity to put theories learnt into practice. Students would graduate and enter the world of work without providing feedback to the training institution regarding aspects that have not been addressed in their training. The reason for this is that the training lacked practical experience. This platform allows students to gain practical experience about 
their career in a community setting while still being supervised by university staff. The student feedback in turn can advise the existing curriculum as to how to incorporate relevant course content into high quality and highly efficacious teaching and training that are informed by responsible and responsive community engagement. The implications of a platform such as MPC is the creations of a highly impactful relationship between the university and its community stakeholders at all levels of social engagement. This article confirms that when the cyclical planning, acting, observing and reflecting principles of action research are rigorously applied, favorable relevant and impactful knowledge creation and the improvement of learning and service outcomes inevitably become the order of the day. For example, this can be seen by the increasing number of clients that attend the MPC each year. At the end of each year the MPC clinic reviews the its demographic and service provision statistics which provide an overview of the types of services rendered by the students to clients in the community. When comparing the different psychological services rendered, the most frequently accessed services are highlighted. This data informs the selection of the category of health science student placed at the MPC for that particular year. One cycle thus informs the other, while enhanced trust and goodwill between the university and its communities are also developed because needs are appropriately identified and addressed.

\section{HIGHER EDUCATION MULTI-DISCIPLINARY HEALTH TRAINING}

Existing research spanning more than 50 years provides global direction for a transformed health professionals' training paradigm. Frenk et al. (2010), for instance, highlighted the social and economic needs of people from developing countries, emphasizing the need for multidisciplinary educational approaches that embrace a range of health and social science disciplines, within such contexts. In South Africa, in particularly, community engagement has been flagged in the White Paper (DoE) as a strategy to enable Higher Education Institutions (HEI) to demonstrate their social commitment and strengthen their sense of social responsibility, in keeping with the changing landscape of South Africa.

Early health curricula did not allow interaction among students of different disciplines and, as a result, students were equipped to function in their own disciplines for their own purposes, only (Beatty 1986). However, since the publication of the White paper in 1997, HEI have prioritized community engagement as an integral part of learning, as well as teaching and research, and not merely as a philanthropic activity (Bender 2008b). In a paper published by Bender in 2008, she indicated that a number of HEI such as the University of the Free State, the universities of Stellenbosch, Cape Town, Rhodes, KwaZulu-Natal, Johannesburg, Western 
Cape, Witwatersrand, and other universities have established an understanding of the potential that engagement holds for transforming education in relation to societal needs. This type of education produces graduates with a sense of social responsibility and an ability to apply the theory of their practice to local developmental issues.

Many community programmes are currently in operation and HEI's have recognized that if the primary function of higher education is to generate and disseminate knowledge, then service learning provides the context to inform and enrich both (Bender 2008a). Service learning has its roots in experiential education and provides students with an opportunity to engage in community service that is tied to course work with the aim of teaching social responsibility and, at the same time, enhancing the livelihood of the community. Service learning in health education is of particular importance as it enhances the quality of patient care and exposes students to the reality of the work place.

Nelson Mandela University’s (NMU) initial community engagement programmes took into account the challenges and highlights of other HEI engagement initiatives when mapping a model within a comprehensive university context. However, the proposed model discussed is an inverted model in that mental health provision is being provided by NMU health sciences students with the assistance from psychiatric services and medical services from Dora Nginza Training Hospital on a sessional basis. Furthermore, this model employs a bottom-up approach in order to prepare students to work in multi-disciplinary health teams. It is further hoped that such a model will act as a precursor to the training of medical students at the medical school that that will become operational in 2020 and will be situated on the Missionvale campus.

\section{METHODOLOGICAL APPROACH}

This article reports on a study which used a combination of observational, self-reflective and narrative techniques to collect data. The authors include two clinical psychologists, an educational psychologist, and a registered counsellor, three of whom work at the Missionvale Psychology Clinic (MPC) on a daily basis. These authors are thus well suited to reflect on the relevant intersecting agendas and practices in higher education mental health training.

Methodologically, the study reported in this article resonates with action research theory in that it retrospectively reviews the cyclical development of a specific university-community engagement project. The article describes part of a larger project during which the establishment and development of the specific case, the NMU's MPC was reviewed and adapted for sustained provision of responsive clinical student training in a community-practice context. The researchers reporting on the study followed the principles of action research as action research 
has, as its primary goal, the facilitation of social change (Chishimba 2013; Neuman 2011). Traditionally, it has been assumed that scientific knowledge is created by specialists, scholars and theorists and is applied by practitioners. However, the type of action research used was that of participatory action learning and action research (PALAR), which provides practitioners the opportunity to create knowledge on the basis of concrete experiences by critically reflecting on experiences, formulating abstract generalizations from it, and testing these newly created concepts (Zuber-Skerritt 2015). By using this approach, new concrete knowledge is gained, thus continuing the next cycle of experiential learning and knowledge creation.

Wood and Zuber-Skerritt (2013; 2015) argue that PALAR is a useful methodology for engaging in educational research with communities for social and educational improvement, especially in the South African educational context, as it is learner centred, process and project based, interdisciplinary, located in real life, aimed at social justice, and based on contemporary cultural concepts. Furthermore, this methodology incorporates concepts and values such as participation, collaboration, communication, community of practice, networking, and synergy, principles which speaks to the project described in this article, whereby interns and students, together with qualified mental health professionals, engage in a multi-disciplinary sustainable service delivery initiative for six days a week, with time built into the programme for reflection and networking.

The research method used relates directly to intervening in a rapidly changing world where shifts in mindsets, creative thinking, transformational learning, and social justice is imperative (Zuber-Skerritt 2015).

\section{BACKGROUND TO THE STUDY: NMU MPC}

The multi-faceted mental healthcare needs in disadvantaged communities have been underreported in developing countries such as South Africa. After 1994, the post-apartheid era brought about many changes in the South African landscape, which notably highlighted the discrepancies in the socio-economic situations of different groups within the country. In particular, Pretorius-Heuchert and Ahmed (2001) mention poverty, the country's history of apartheid, and differentiated belief systems, as aggravating societal factors. For example, Truter (2007) reports that in 1995, 200000 healers were practicing in South Africa compared to 25000 modern doctors, and it is estimated that up to 70-80 per cent of the population in Africa consult a traditional healer before going to a primary health care practitioner. The combination of the above factors has resulted in the aggravation of a variety of strong poverty linked health-related symptoms and diseases. 
At the NMU's MPC in Port Elizabeth, a large industrialized metropolitan area on the south coast of South Africa, the convergence of these factors in a specific underserviced and impoverished urban township is clearly visible. The leading causes of deaths in this area, which is loosely called Missionvale, are HIV $\backslash$ AIDS and other communicable diseases, perinatal conditions, and nutritional deficiencies. Road accidents are also a leading cause of death in the 5 to 14 year age group (Bradshaw et al. 2006; ESCEC 2014). Disconcertingly, statistics furthermore indicate that mental health symptoms seem to be under-reported in this area. For example, the municipal clinic in the area only reported two patients who were diagnosed with mental health problems in 2015 (Bradshaw et al. 2000). A possible reason for this is that the municipal clinics are understaffed and nearly exclusively and primarily deal with life and death crises, which legally need to be formally reported. Consequently, urgent but non-life threatening and systemic health problems are often overlooked, underreported and undocumented. Furthermore, there seems to be a reticence among trained professionals to work in these communities due to the threat of burn-out, traumatization and the need for socially sanctioned and economically viable professional success.

Within this contextual setting, a university-based training intervention can contribute to addressing these pressing problems, both in terms of relevant and responsive clinical and practical training of students and the servicing of community needs. NMU's MPC has, since 2014, been actively involved in this challenging setting. Geographically the area called 'Missionvale' is not a recognized municipally designated area in the Nelson Mandela Bay Metropole, but is grouped within the larger Bethelsdorp area. However, the university campus situated in this area and the psychology clinic located on its premises is called the Missionvale campus and clinic, and this is also the name colloquially used by many residents and officials who live and work in the area. For these reasons the article will refer to the geographical area as Missionvale.

\section{Missionvale}

Missionvale is a densely populated, low income area in the northern areas of Port Elizabeth with an estimated population of 182012 (Department of Health 2015. The MPC serves an area with over 19000 people, with approximately 14000 children under the age of 14, and 550 people over the age of 74, having been seen at the clinic in 2015 (Department of Health 2015).

There is currently a focus by the Nelson Mandela Bay Municipality on upgrading the structural living conditions in the Missionvale area, but at the time of writing this article, 19 per cent of the households did not have piped water inside their dwellings, 10 per cent did not have 
access to electricity for lighting, and 17 per cent of the households did not have weekly waste removal (ESCECC 2014). The community regularly complains that municipal services are poor, leading to regular riots in the area (Pinyana and Witten 2015). The municipality, in turn, has reported that the increase in the number of households is putting additional pressure on service delivery and infrastructure (Frith 2011).

The effects of a lack of education link directly to poverty and health (Lacour and Tissington 2011). In relation to education and employment, some of the current challenges in Missionvale, which is reflective of the Eastern Cape Province as a whole, are that 70000 of the adults in Missionvale have not attended school at all, and the number of learners passing their final year of schooling has steadily declined, with the pass rate having deteriorated to 56.8 per cent by 2015 (Child 2016).

In Missionvale 34 per cent of families live below the poverty line (Frith 2011), and the level of active employment is 27 per cent in the Eastern Cape when compared to active employment in South Africa as a whole (ECSECC 2015). A high level of crime is also present with 195 reported murders in 2010 (ECSECC 2014), while crimes such as family violence and rape often go unreported.

\section{Higher education community engagement}

Universities that see themselves as 'engaged institutions' are those in which community engagement is infused in all teaching, learning and research activities (Bender 2008a). Community engagement is essentially a planned, problem-solving process and includes deliberate action intended to alter a situation, and furthermore implies a reciprocal and inclusive relationship between a community and a HEI. According to Bender (2008b), there are three main historically established activities of a university, namely teaching, research and community engagement. The trans-disciplinary mental health platform discussed in the article employs an infusion model of all three fundamental activities as outlined by Bender (2008b), with community engagement considered to be the central overriding goal of higher education.

NMU's strategic vision, called Vision 2020, and its institutional Engagement Framework emphasize the significance of integrated and responsive community-based engagement. As an initiative of the university, located on one of the university's six campuses, the MPC is ideally situated to address the university's practice-based teaching and learning agendas in collaboration with rendering a responsive and responsible outreach platform to the underserviced communities in the immediate vicinity of the Missionvale campus.

However, a major institutional challenge is that the current status of community 
engagement seems to be limited to insular projects, with a lack of trans-disciplinary collaboration between historically situated silos within the university. For instance, students initiate projects in communities, collate the data, and then use the data to further their own education and career prospects beyond graduation. However, the research findings, recommendations and practical skills gained from these communities are often not channeled back to the same communities. Thus there exists a disjuncture between community expectations and student application. The expected assistance, implementation of recommendations, and feedback to communities are often perceived by the communities as being withdrawn once students have completed their modules or qualifications and the services are then not available until the next project, which may again require community involvement. As a result, communities become research fatigued and may feel exploited. An effective community-based health provision platform is thus needed to provide sustained service delivery by the university and its students. In addition, Pillay (2003) says that the present format for the training of mental health professionals in South Africa is ineffective and needs to be revisited. The underlying problem is an abundance of people with psychological problems and too few people in health care to assist them, particularly in underserviced and impoverished areas.

There are many speculations about the reasons for this scenario. Reid and Conco (1999) note that the post-apartheid government introduced a post-university community service year for graduating health professionals; however, due to limited community engagement and lack of preparation during their initial training, the students are exposed to challenges in the medical, teaching and psychological setting for which they are not prepared or adequately trained. The role of the university is thus crucial in preparing graduates appropriately for their community service year. Reid (2000) asserts that this can be achieved by introducing community experiences into pre-graduate training, in which case the community service year which is mandatory for most health-care professionals can then be regarded as a 'test-drive' of their products, on a challenging test ground.

The existing health care training model is also not geared towards making adjustments to standardized conventionally accepted techniques or learning appropriate alternative methods of intervention. Pillay (2007) reports that a plethora of community projects and interactions built into the curriculum can provide psychologists with the necessary skills they need in order to work with a community's problems, but that this does not address the ebb and flow or exploitation experienced by communities. The authors acknowledged the above-mentioned challenges and attempt to address these obstacles by way of the trans-disciplinary community mental health student teaching and learning platform described in this article. 
Health professionals trained in South Africa can work globally at an acceptable competitive level if they hold accreditation from their profession-related boards which dictate their scope of practice. The training must therefore meet the criteria of both first and third world requirements. The curricula proposed by these professional governing and accreditation boards regulating the professional standards tend to follow a predominately medical western model, which does not always take into account the unique challenges and needs often found in developing countries and underserviced communities.

In response to the dynamic and rapidly changing health challenges faced by the local communities in the Nelson Mandela Bay Municipality (NMBM), the NMU Faculty of Health Sciences (FHS) has adopted a bottom-up approach to the training of its students (currently in implementation), who will become accredited professionals practicing in a variety of setting across the globe. This approach has both short and medium range objectives which include the following: 1) the provision of health and social development training to undergraduate and postgraduate learners through experiential inter-professional training in a community-based context; 2) to improve the relevance of health professionals' education within the FHS at NMU through the establishment of a trans-disciplinary consolidated platform; 3) to be accountable to the community it serves; and 4) the development of curriculum transformation to establish a trans-professional relevant and responsive curriculum. Despite all the challenges, transformative teaching has been one of the teaching methodologies which has guided this mental health student teaching and learning platform.

Transformative teaching has its roots in Mezirow's theory, which highlights that both actions and behaviours will be changed based on changed perspectives (Cranton 1994). Cranton (1994) claims that if basic assumptions are never challenged, change is not likely to take place and mentors at university will continue to have a set of assumptions that guide teaching practices. Transformational teaching based on the above-mentioned theory can thus be seen to include experiential learning, problem-based learning, and collaborative and student-based learning (Slavich and Zimado 2012. Boyd (1989) claims that transformative learning outcomes include a change in self, and what the authors of this article conceptualize as a more fit-forpurpose student in an ever-changing world. This initiative has encouraged developmental professionals in the health sciences to balance their teaching practices, which focused strongly on knowledge and skills, with the creation of opportunities in which the faculty provides the health professional students with opportunities to critically reflect and engage in heart and soul learning. Indeed, multi-disciplinary health practices are starting to evolve from 'silo-practices' between different professionals, to team initiatives on the current teaching and learning 
platform, with each member of the team being an integral puzzle piece in mental health service delivery. Both the benefits and challenges of this experiential type of mental health intervention practice will serve to inform the incoming medical students who will enroll at the new medical school in 2020, with community mental health services being packaged as primary health care and forming an integral part of all health science students' curriculum and not as an 'add on'.

\section{GUIDELINES TO INFORM THE DEVELOPMENT OF A TRANS-DISCIPLINARY COMMUNITY MENTAL HEALTH STUDENT TEACHING AND LEARNING PLATFORM}

Based on the principles of action research, teaching and learning, higher education engagement, and the mental health team, the MPC has played a part in molding the thinking of the mentors involved with curriculum development. During the authors' reflection on the development of this trans-disciplinary platform, certain processes emerged that facilitated the operational change in community service delivery. These changes have resulted in the perceived success of this venture by both the community and the researchers, as evidenced in an increased number of client referrals, a formal memorandum of agreement that was recently signed between the Missionvale Care Centre (MCC) and the university, increased referrals from schools and NonGovernmental Organisations (NGOs), and face-to-face interaction with the head of the psychiatry department at the provincial hospital which also serves as a training unit for specialists. The following section describes the guidelines for developing a trans-disciplinary, mental health student teaching and learning platform, taking into consideration the steps taken and the lessons learnt. A visual representation of this framework is indicated in Figure 1.

\section{Step One: Profiling}

To develop a community mental health platform for service delivery and to replicate a 'real work' experience for students, it is essential to first profile the community. This was done using municipal statistics and statistics from the municipal clinic and the MCC, and meeting with ward counsellors, the Department of Health, and the Department of Education. Additional information was gleaned from referral agents in the community which included schools, social development agencies and NGOs dealing with rape and HIV.

Profiling of the Missionvale community revealed an operational site that is geographically located in an underserviced community and is suited to provide a multi-disciplinary service delivery initiative that can grow to incorporate numerous medical and educational services that this community has not been able to access in the past. While a medical training facility will be 


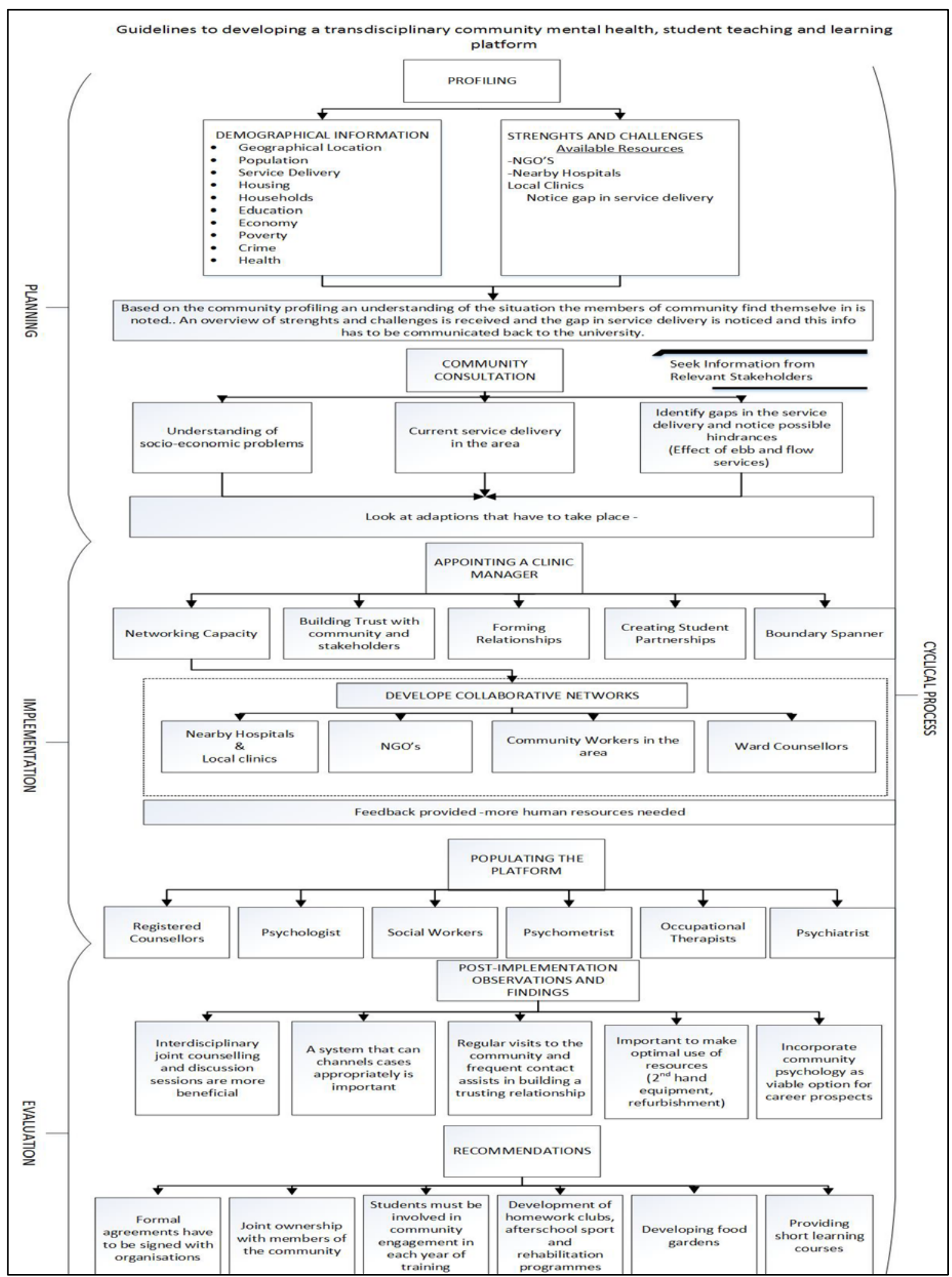

Figure 1: Guidelines to developing a trans-disciplinary community mental health, student teaching and learning platform

established by 2020, for now, the university’s existing psychology clinic on its Missionvale Campus fits the requirements for multi-disciplinary interventions. From this site the researchers 
were able to gain insight into the strengths and challenges of this particular community. Furthermore, stakeholders such as Dora Nginza Hospital, the Faculty of Health Sciences and the MCC, provided an opportunity to identify and address the changing needs of the community. The authors are aware that profiling is not a once-off exercise as the dynamics of a community constantly change and thus such an activity should be an iterative and cyclical process that is conducted on an ongoing basis. While basic nutritional and health care needs will always remain a priority in underserviced communities, the initial profiling in Missionvale re-emphasized the need to prioritize these primary services on an ongoing basis

Social media and school principals have also alerted the MPC to the high incidence of drug abuse, but limited referral numbers indicate a resistance to seeking assistance with these problems in this area. This issue may necessitate psycho-educational intervention in the schools in the Missionvale and surrounding areas. More than half of the current referrals are made by NGOs, indicating that parents are not aware of what psychological services entail and how they can be accessed. In light of the above, it is evident that community health care and community education intersect as an area of intervention for the MPC and the health sciences students of NMU. Due to the MPC's low fee structure and advocacy from institutions in Missionvale, referrals are starting to be received from other geographical areas in the Metropole.

However, for students to have access to appropriate training grounds and be involved in providing various mental health services to underserviced communities, such as those in Missionvale, a number of factors have to be taken into consideration. Firstly, the demographics of the area need to be understood, which is an important function of a profiling exercise and, secondly, the community's strengths and challenges must be reported and understood.

\section{Demographic information}

Demographic statistics provide some understanding of the lived experiences of members of a community and can be obtained from local government, local and national police services, local hospitals and clinics, NGOs, and schools. Such statistics would include looking at the geographical location, population survey, present service delivery in the area, housing structures (as in brick structures or informal housing), the average size of households, number of individuals per household, the general educational level of the community, socio-economic status, poverty level, crime rates, and the overall health status of the community.

\section{Strengths and challenges}

After gaining an understanding of the demographical factors involved, further information is 
needed regarding the existing strengths and available resources within the community itself so as to avoid replication of existing well supported aspects, and to ensure identification of the significant gaps in service delivery. The latter is particularly important as students will need to learn to refer appropriately. For example, the community members involved with the families should, through advocacy of services, know to which professional a rape victim should be referred. Should it be the doctor, the psychologist or the social development office? Each health professional is therefore responsible for making their availability and scope of practice known, in order for people in the community to know where these professionals can be found, and what the most effective means of communication are. It is important to understand the belief systems of the community and, if necessary, involve traditional healers in the healing process. Therefore, connection should be made with spiritual leaders and all effort should be made to incorporate them into the 'helping team' for supporting the community.

During the community profiling phase of the project, it emerged that a pastoral care centre, the Missionvale Care Centre (MCC), had existed in this community for 27 years and, despite not receiving a government subsidy, has provided limited nutrition, clothing, clinical care, pharmaceutical treatment, and spiritual care to the most needy in the community. This facility was viewed by the community as a trusted one-stop-shop to meet their basic physiological needs; however, limited psychological services were available to assist the MCC with the emotional challenges presenting at the facility.

Based on the community profile, it was noted that the MPC is ideally situated to render a responsive and responsible outreach platform to the underserviced community in the immediate vicinity of the Missionvale campus, in collaboration with the existing MCC. Furthermore, an understanding of the strengths and challenges allowed the university to address the need for relevant community-centred practice-based teaching and learning, while avoiding the exploitation and research fatigue pitfalls explained earlier.

\section{Step Two: Consultation and collation of information from relevant stakeholders}

Community engagement is part of a larger stakeholder engagement strategy for any university. By consulting the relevant stakeholders such as community leaders and organisations in the area, a clear picture of community functioning can be formed. Community consultations provide the opportunity to gain a better understanding of the community and buy-in from relevant stakeholders. Trusting relationships can be formed at an early stage and sustained throughout the cyclical development of the initiatives and interventions. Furthermore, community consultations help to ensure that service providers are responding appropriately to 
the immediate and pressing needs of the community, providing a clear and reliable contextual understanding and blue print of a community, and its existing strengths and needs. In the case of the MPC, for example, conversations with stakeholders in the community highlighted that the service provision from the pastoral Missionvale Care Centre (MCC) created the community expectation of a five-day service delivery time frame and that off-site home-visits were an expectation and pressing need which has been initiated and provided by the MCC. In order to instill service credibility, time frames of longer than a month, which were common before the creation of this platform, were eliminated by the MPC and on-site home-based care is being introduced to students as an alternative to traditional consultation practices. Community consultations provided the following information:

- An overview of the types of socio-economic and systemic issues prevalent in the community (drug abuse, sexual abuse, teenage pregnancy, family violence and HIV/AIDS). This information was communicated to the academic teaching staff of the university via a trans-disciplinary health professional's forum meeting in order to facilitate adaptions to the curriculum in an attempt to respond to these challenges. It was recommended that service delivery take the form of internships which serves the community for longer periods, unlike that of insular modules. It also became evident that a permanent staff contingent based at the MPC delivery site at Missionvale Campus was essential to co-ordinate community activities and act as a boundary spanner between the community, stakeholders, university management, and its academic staff and students.

- $\quad$ The physical distance between the university's main campus, where its health sciences students are taught, and the Missionvale campus and MPC, is $22 \mathrm{~km}$. This physical distance was also reflected in perceptional and attitudinal distance, which created problems with communication, transport, isolation and marginalization, and can only be addressed through active involvement and transcendence of physical, disciplinary, institutional and professional boundaries and distances by all parties concerned.

\section{Step Three: Appointing a Clinic Manager}

In 2014, a full-time Clinic Manager was appointed in the MPC on the Missionvale Campus. This consolidated the university's commitment to community collaboration with the Missionvale Community and the integrated management of student community-based training. The role of the Clinic Manager is to: 
- $\quad$ develop collaborative networks;

- $\quad$ build trust with the community;

- $\quad$ educate and advocate for psychological service in such a manner that referral will come from households in the community rather than hospitals and NGOs;

- facilitate student partnerships from different disciplines within the Health Sciences Faculty;

- $\quad$ monitor and provide feedback to the university and academic staff on the functioning of the students in the field.

\section{Step Four: Develop referral systems with existing community organisations and NGOs in the community}

Through the Clinic Manager, strong collaboration networks were established with Dora Nginza Hospital's psychiatry department (the hospital closest in proximity to the MPC), the Missionvale Care Centre (MCC), community workers employed by the MCC, and presently a new liaison with the Department of Health is being negotiated with the Faculty of Health Sciences.

Regular feedback from the Clinic Manager to responsive leaders in these organisations resulted in a psychiatric registrar and a hospital-sponsored clinical social worker being assigned to the MPC on a weekly basis. This marked the beginning of a collaborative multi-disciplinary approach which resulted in more effective referrals and better treatment interventions - for example, the most severe mental health cases (which would have likely gone undetected or unattended before) were immediately referred for appropriate medical care.

\section{Step Five: Populating the platform with staff and students and with trans- disciplinary skills}

The platform was populated with the following professional categories:

\section{Psychology}

In 2014, three registered counsellors requiring compulsory student internship placements were assigned to the clinic. The core scope of their work consisted of psycho-educational interventions, psychometric screening and school readiness assessments in the Missionvale area. These students also visited schools and met with community members which extended the reach of the MPC and the effectiveness of its community profile and network, and further formed a first base-line experience in intern-practice in Missionvale through the facilitation of 
the MPC. This type of community engagement enabled the clinic to be seen in a more positive manner, mainly as a result of the visibility of the staff in the community, speedy service delivery, and trust and networking. As a result, closer relationships were formed with the surrounding institutions needing assistance, which included the hospital, the municipal clinic, the NCC, and NGOs and schools. Almost immediately, the requests from schools increased as only one educational psychologist per district has been recently appointed.

\section{Social work}

At the same time, two social work interns were placed in the clinic as part of their degree requirements, and worked closely with the registered counsellors to present psycho-educational activities, assertiveness training and anger management to community members. While each discipline (psychology and social work) maintained and practiced their core professional functions, together they were able to address stressors in both counselling and workshop interventions. The manager continually facilitated such student partnerships within the distinct heath science disciplines, and furthermore, provided feedback to the university academic and teaching staff on the challenges in the community in an attempt to bridge the gap between theory and practice in the classroom and teaching environment.

The social work students were based at the MCC for three days a week due to insufficient office space at the MPC. In hindsight, this was advantageous due to their visibility within the community. The fact that the students worked in the area on a daily basis also facilitated trust within the community, as testified by both the community workers and the staff at the MCC who had been previously disillusioned by the perceived ebb and flow of the university's involvement in the community.

\section{Psychiatry, clinical social work and occupational therapy}

Through networking and regular contact sessions with the Department of Psychiatry and the Head of Psychiatry from the Dora Nginza hospital located closest to Missionvale, a psychiatric registrar was allocated to assist the MPC on a weekly basis. The involvement of the hospital is growing exponentially, with the addition of occupational therapists, a psychologist and a clinical social worker providing services on a weekly basis at the MPC site in Missionvale since 2014. At the end of that year, a second senior psychologist was appointed to assist with the acceleration of the university's community engagement vision. In 2016, the team grew with two occupational therapists, forming the Ukhanyo Clinic (meaning 'Light'), which marks the first step towards a trans-disciplinary service delivery initiative. 


\section{Managing trans-disciplinary and community integration}

The practicum semester for both registered counsellors and social work interns after June 2015 swelled the staff complement to four registered counselling students and a qualified registered counsellor, which increased staff resources and, consequently, the MPC's service provision. An intern psychology student was allocated to work at the MPC during the week, and masters' students received their in-service training there over weekends. This continued service assisted with faster intake times and therefore a reduction in the long waiting list. Previously, student interns from the Department of Psychology spent the majority of their time working at the MPC, except for workshops held in the community; however, at present, time in the community is increasing. These interns receive weekly supervision from MPC staff members, thus promoting in-service training, but also trans-disciplinary interactions with other mental health professionals from divisions of medicine, social work, and in the future, from dietetics, human movement practitioners, graduate psychiatric nurses, and occupational therapists.

The permanent staff members of this trans-disciplinary platform at the MPC are meeting on a monthly basis with the university's academic project team to sustain and improve the transprofessional services that have started to emerge. Thus, a wider variety of, and more effective and relevant mental healthcare, social and educational services are developing in this community which, for example, have special needs schools for the physically disabled, blind and deaf within a three kilometer radius and contain a large number of geriatric people as part of its population. The trans-disciplinary platform has paved the way for a number of projects that have evolved as a direct result of this initiative, including support groups for care workers; individual consultations and health promotion activities; psycho-educational workshops on protective behaviors, sexuality and self-esteem; HIV support groups; and career guidance for blind learners. With the inclusion of a variety of health professionals, these projects can now be extended to include nutrition, rehabilitation, as well as longer term therapeutic intervention after hospitalization.

By introducing and exposing students to the community on a regular basis, this exercise could create a supportive environment for students whereby they do not feel overwhelmed by the reality of community work. Consequently, graduating students may be better prepared for their community service year - which is compulsory before they can register to work within their professional scope. This new approach to practicing health interventions in a multidisciplinary manner may hopefully encourage students to retain the ethic of community care in their private practice after graduation. 


\section{Step Six: Post-Implementation observations and findings}

This section summarizes the most important lessons learnt during the development and implementation of the MPC, and makes some general observations on the successes and challenges experienced. This may be of use to peers in academia or in community practice who can use these comments and observations in their own practice.

1. It was perceived that social work students initially seemed to be more open to community work and to reflective interactive experiences than students from other disciplines, like psychology. Possible reasons for this could be the early exposure to community activities in social work curricula and training, and better language proficiency in the language of the community.

2. Peer contact between social work and psychology students through the MPC initiatives contributed to what is perceived as an earlier and positive attitudinal change in psychology students towards community work.

3. Active advocacy in the community regarding the types of services rendered is essential in setting up community structures and ensures appropriate referrals, for example, networking with schools, hospitals, NGOs and policy-making departments such as the Department of Health and the Department of Education

4. Regular visits to the other organisations that service the same community assisted with open and honest communication, effective referrals, reducing duplication, as well as the collective reorganisation of the types of available services from time to time, as required by community needs.

5. Interaction between the different organisations is often personality-driven: Not all people have an equal interest in, or passion for, community work. Although everyone should be professionally trained and aware of the theory and practice of community psychology, those who are internally driven to contribute to this field will emerge as champions for community work. However, because of the high levels of burnout and fatigue, care should be taken to support these individuals effectively in both their personal lives and professional practice.

6. Health professionals working in the community need to be seen outside of their offices, that is, on the streets and in the homes of the community. For example, they must be prepared to assist with trauma at schools where a group of people are involved, or to assist with a variety of support groups such as trauma counselling, maternal mental health 
support and HIV\AIDS support groups.

7. Resourcing the MPC with the necessary equipment was partially dependent on donations and the good will of businesses as a budget for this type of training rarely attracts funding. Creative ways of sourcing funding for operational and strategic income invariably form a large part of the management of an initiative such as the MPC.

8. Community psychology should be promoted early among students, in such a way that it can become a clearly viable career path with perceived professional upward mobility.

9. For students, being exposed to different health science professions, practices and paradigms in their training opened up valuable insights into the complexity of community patient care. It also challenged them to consider alternative treatment and interaction options and encouraged them to improvise possible innovative solutions to community care problems.

10. The old adage that more hands make lighter work has proven true - the appointment of a part-time psychologist eased the therapy burden for the psychiatric staff, who could then apply themselves more effectively where they were needed and trained to intervene.

11. An increased number of students populating the MPC as part of their student experience allowed for a smoother transition between the already established mental health professionals and a more holistic approach among the professions in general.

12. It was evident that, for community members, being able to see more than one health care professional in a single physical space was more effective and led to better appointment and treatment compliance.

13. Collaborative relationships in the university's Faculty of Health Sciences and with stakeholders in the community are starting to broaden as a result of the intermediary role played by the MPC, thus bringing the proverbial 'town' and 'gown' in more effective contact and relationship with one another.

14. Language barriers are often debilitating causes of ineffective service delivery in communities, for example, in Missionvale the predominate languages spoken are isiXhosa and Afrikaans.

\section{Step Seven: Implications for practice}

Based on the above observations and the lessons learnt during the development and establishment of the MPC, the following suggestions are made for the next cycle of adaptations, planning, improvement and review: 
1. Formal agreements with the community organisations are essential to consolidate networking and solidify collaborative work.

2. In all initiatives and communications with the community, community members should be encouraged to take joint ownership for their welfare and to be actively involved in caring for the community in which they live. The communalist value of Ubuntu (a person is a person because of other people) then becomes a guiding principle for the practice of community work.

3. Health sciences students need to be involved in community engagement in each year of their training, working with different levels of information and exposure according to their level of training. This involvement needs to be built into the curriculum, and the intervention needs to become more advanced as the students' progress through their courses. This strategy is one way in which the students can assist in promoting basic mental health principles in communities and assisting with field work in academic research projects, while also internalizing the values and principles of community health care for their future professional practice.

4. Homework clubs supervised by students and members of the community are envisaged in the MPC in the next cycle. Since the beginning of 2016, the university's Foundation Phase Education students are also being trained at the Missionvale campus. This type of involvement will create new opportunities for homework clubs which have been requested by learners, parents and schools, and will also create opportunities for the remedial assistance and tutoring of learners. In addition, this venture provides an opportunity to increase the interdisciplinary collaboration in a field other than health, namely education, thereby affording children the opportunity to study in a safe environment on campus and under the supervision of trained educators.

5. At the MCC, community gardens are being implemented under the guidance of the university’s Department of Agriculture and Game Management to provide opportunities for undergraduate students with modules pertaining to community engagement to get involved in and assist the community to take ownership of such a project.

6. Extra-mural activities and rehabilitation programmes can be initiated by the university's Lifestyle and Human Movement Sciences Department as no such activities exist in the area. Basic physical exercise activities with children (for example, as part of homework clubs during vacation breaks) and with the aged waiting at the MCC for consultations and food allocations could be introduced, as well as the training of those who care for the disabled or aged in the community. Again, trans-disciplinary interaction holds potential 
for holistic learning for all concerned across a variety of traditional 'disciplines' which could include agriculture, education, natural sciences, nutrition, food management, human movement science, occupational therapy, psychology, pharmacy, environmental health, and clinical care.

7. A recent need among the community that emerged following the advocacy of psychological services in the area is that of school readiness assessment. Combining these with other services rendered by the MPC will address systemic problems in a more holistic manner and facilitate intervention and appropriate referrals at the earliest instances.

8. Similarly, medical clinics for women have emerged as a community need and will provide a platform for early health interventions, whereby occupational therapists, together with registered counsellors, will have the opportunity to teach mothers about early childhood stimulation and child care. Early childhood development groups will form part of service delivery at the MPC in the future.

9. Short learning courses on a variety of topics can be developed to train the community in a range of skills, which could contribute to increasing life skills and employability prospects. This endeavor could expand to include the development and presentation of short learning courses for educators at schools in the area, thus becoming 'train the trainer' initiatives and multiplying the effect of the MPC and its services. For example, such courses are envisaged to assist educators to identify the various barriers to learning in the classroom.

10. Short courses for translators are also needed in order to reduce the language barrier between the students and the community, by introducing both demographics to a broader range of basic communicative and expressive problem-solving and diagnostic languages. Translation between English, Afrikaans and Xhosa are essential in the Missionvale area, but other languages also feature prominently, especially due to the influx of people from other regions in South Africa and foreign nationals to the urban area of Nelson Mandela Bay. For example, students who are fluent in Xhosa carry a heavier client load at present, since this is the more common lingua franca in Missionvale. It is therefore recommended that Xhosa be a compulsory short course for all students studying in the health sciences at NMU.

\section{CONCLUSION}

This article described and recorded the establishment of a trans-disciplinary mental health platform as part of a South African university’s community outreach and service training 
agenda. It recorded the background to the establishment of the MPC, a unique multidisciplinary university-community collaborative initiative in South Africa, identified lessons learnt, and furthermore created a suggested blueprint for the establishment of similar projects in other communities through observation and recommendations. This framework will inform the next cycle in the development of the MPC, but could also benefit other initiatives and serve as a basis for future comparative studies with similar university and/or community projects, both nationally and abroad.

Thus far into the initiative, we are witnessing a movement towards transformative learning, with collaborative interaction serving as its foundation. In order to continue along this path, it is imperative to nurture this type of learning, possibly formalizing it by way of signing a memorandum of agreement in the future.

As a case, the MPC is unique because of it localized situatedness, but it also serves as a fertile general test case and living laboratory for other similar communities and developing countries facing many of the same challenges. It is often noted in academia and the health sciences professions that there is a tendency for professionals to work in silos, even when there are clearly identified common goals. However, it is the view of the authors that the MPC, in its first cycle of implementation, has managed to break down some of these silo-centred patterns within academia and the health professions, and will continue to do so in future cycles of adaptation, planning, implementation and review at the MPC. Indeed, collaborative engagement between the university and its stakeholders, including underserviced and impoverished communities, are at the core of the MPC as a sustainable venture. Moreover, such collaborative efforts provide essential services to a community that would otherwise have no or little access to such services, while also providing the university's students with an opportunity to integrate theoretical work with practical application, thereby contributing to the improved relevance, versatility and quality of health practitioners in South Africa.

\section{REFERENCES}

Bandura, A. 1986. Social foundations of thought and action: A social cognitive theory. Englewood Cliffs, NJ: Prentice-Hall.

Beatty, P. R. 1986. Attitudes and perceptions of nursing students towards preparation for interdisciplinary health care teams. Journal of Advanced Nursing 12, 21-27.

Bender, C. J. G. 2008a. Curriculum enquiry about community engagement at a research university. South African Journal of Higher Education 2, 189-194.

Bender, G. 2008b. Exploring conceptual models for community engagement at higher education institutions in South Africa. Perspectives in Education 26(1): 81-96.

Bradshaw, D., P. Groenewald, R. Laubscher, N. Nannan, B. Nojilana, R. Norman, D. Pieterse, M. Schneider, D. Bourne, I. Timaeus, R. Dorrington and L. Johnson. 2000. Initial burden of disease 
estimates for South African 2000. South African Medical Journal 93(9): 682-688.

Bradshaw, D., N. Nannan, R. R. Laubscher, P. Groenewald, J. Joubert, B. Nojilana, R. Norman, D. Pieterse, M. Schneider. 2006. South African national burden of disease study: Estimates of provincial mortality (Eastern Cape Province). http://www.mrc.ac.za/bod/pdf

Boud, D., R. Keogh and D. Walker. 1985. Reflection: Turning experience into learning. London: Kogan Page.

Boud, D. 1999. Avoiding the traps: Seeking in good practice in the use of self-assessment and reflection in professional courses. Social Work Education 18(2): 121-132.

Boyd, R. D. 1989. Facilitating personal transformation in small groups, Part 1. Small Group Behaviour 20(4): 459-474.

Child, K. 2016. Matric 2015: SA’s biggest provinces flop. Rand Daily Mail, 6 January. http://www.rdm. co.za/politics/2016/01/06/matric-2015-sa-s-biggest-provinces-flop

Chishimba, F. N. 2013. Raising student teachers' awareness around issues of professional conduct: An Action Research project. Unpublished master's thesis, Rhodes University, Port Elizabeth, South Africa. http://contentpro.seals.ac.za/iii/cpro/BrowsePage.external?lang=eng\&sp=Qchishimba+ raising+student+teachers\%E2\%80\%99+awareness+around+issues+of+professional+conduct\%3 $\mathrm{A}+$ an+action + research + project \&sp=Ru1000001\% 40\&sp=-1\&sp=X\&sp=X\&sp=SChishimba+ Raising+student+teachers\%E2\%80\%99+awareness+around+issues+of+professional+conduct\%3 $\mathrm{A}+$ An+Action+Research+project\&suite $=$ def

Clark, P. 2006. What would a theory of inter-professional education look like? Some suggestions for developing a theoretical framework for teamwork training. Journal of Interprofessional Care 20: 577-589.

Cranton, P. 1994. Self-directed and transformative instructional development. Journal of Higher Education 65(6): 726-744.

Department of Health. 2015. Pivotal tables: Missionvale Municipal Clinic for period March 2014 to April 2015. Eastern Cape, SA:

Eastern Cape Socio Economic Consultative Council. 2014. 2014 Socio-economic profiles for the Eastern Cape Province, Metros and District Municipalities (NMBM profile). http://www.ecsecc. org/news-article/80/2014-Socio-Economic-Profiles-for-the-Eastern-Cape-Province-Metros-andDistrict-Municipalities (accessed September 2015).

Eastern Cape Socio Economic Consultative Council. 2015. Eastern Cape unemployment drops to 29.1\% in second quarter of 2015. http://www.ecsecc.org/news-article/83/Eastern-Cape-unemploymentdrops-to-291-in-second-quarter-of-2015

ECSECC see Eastern Cape Socio Economic Consultative Council.

Frith, A. 2011. Collated from StatsSA Census 2011 Community Profile Databases and Census. http://census2011.adrianfrith.com/

Frenk, J., L. Chen, Z. Butta, J. Cohen, N. Crisp, T. Evans, H. Fineberg, P. Garcia, Y. Ke, P. Kelly, B. Kistnasamy, A. Meleis, D. Naylor, A. Pablos-Mendez, S. Reddy, S. Scrimshaw, J. Sepulveda, D. Serwadda and H. Zurayk. 2010. Health professionals for a new century: Transforming education community profile databases and census. Strengthen health systems in an independent world. doi: 10. 1016/S0140-6736(10)1854-5

Lacour, M. and L. D. Tissington. 2011. The effects of poverty on academic achievement. Educational Research and Reviews 6(7): 522-527.

Mann, K., J. Gordon and L. Macleod. 2009. Reflections and reflective practice in health professions: A systematic review. Advances in Health Science Education 14: 595-621.

Neuman, W. L. 2011. Social research methods: Qualitative and quantitative approaches. Boston, Massachusetts: Pearson Education Inc.

Pillay, J. 2003. Community psychology is all theory and no practice: Training educational psychologists in community practice within the South African context. South African Journal of Psychology 
33(4): 261-268.

Pillay, J. 2007. Teaching community psychology in South Africa. Community psychology. Analysis, context and action. Cape Town Town: UCT Press.

Pinyana, M. and L. Witten. 2015. Violent school protest rock PE. Cape Argus, 28 July. http://www.iol. co.za/news/crime-courts/violent-schools-protests-rock-pe-189145

Pretorius-Heuchert, J. W. and R. Ahmed. 2001. Community psychology: Past, present and future. Community psychology: Theory method and practice. Oxford University Press Southern Africa.

Reid, S. J. and D. Conco. 1999. Monitoring the implementation of community service. South African Health Review 87(3): 293-298.

Reid, S. J. 2002. Community service for health professionals. Health Systems Trust 8: 135-160

Slavich, G. M. and P. G. Zimado. 2012. Transformational teaching: Theoretical underpinnings, basic principles, and core methods. Educational Psychology Review 24(4): 539-605.

Truter, I. 2007. African traditional healers: Cultural and religious beliefs intertwined in a holistic way. South African Pharmacy Journal 74(8): 56-60.

Wood, L. and O. Zuber-Skerritt. 2013. PALAR as a methodology for community engagement by faculties of education. South African Journal of Education 33(4): 1-15.

Zuber-Skerritt, O. 2015. Participatory Action Learning and Action Research (PALAR) for community engagement: A theoretical framework. Educational Research for Social Change 4(1): 5-25. 